\title{
6 The role of public places in Disability Hate Crimes (DHCs)
}

\author{
Antonio Iudici and \\ Riccardo Girolimetto
}

\subsection{Introduction}

Disability Hate Crimes (DHCs) is an under-reported phenomenon concerning any criminal offence considered to be motivated by hostility/prejudice against a person's actual or perceived disability. In this chapter, we identify any potential relationship that may exist between DHCs and public places in the extant literature in order to shed light on the role of such places in facilitating or hindering the occurrence of DHCs. "Public places" here is considered to be a large array of environments, such as urban areas, towns, buildings, but also social networks, where interactions between two or more ordinary people take place. In addition, wherever appropriate, the type of crimes reported and/or the preventive strategies characterizing these spaces are also discussed. To achieve this, Scopus, PubMed and Scholar databases were used to perform a scoping literature review by searching for keywords related to "disability hate crime". Why is this an important subject? (1) Fear, harassment and violence permeate the everyday lives of many disabled people in private as well as in public spaces; (2) most studies often neglect the role of environments in facilitating or hindering DHCs, situating these violent acts against disabled individuals in anonymous physical settings; and (3) it is necessary to locate disability as a cultural and political phenomenon contextualized within society, yet the literature on this field is lacking.

The structure of this chapter is as follows. The chapter starts with theoretical background, which is an overview of definitions: $\mathrm{HC}$ and DHC and theoretical frameworks dealing with disability. This is followed by the methods section, a description of the literature review, and data collection. Results are followed by conclusions and recommendations.

\subsection{Theoretical background}

\section{An overview of definitions: $\mathrm{HC}$ and $\mathrm{DHC}$}

The term 'hate crime' (HC) is generally used to define an act of violence, verbal or physical, in which the offenders target victims for their actual or perceived ethnicity, color, religion, disability, sexual orientation, gender, or national 
origin (Brereton, 2013; Macdonald, 2015; Sun, 2006). This broad definition finds its own genealogy within several US legislations of the twentieth century, such as the Hate Crime Statistics Act of 1990 and the Violent Crime Control and Law Enforcement Act of 1994 (Sun, 2006). Owing to these and other legal definitions, most previous researchers of $\mathrm{HC}$ tended to frame this phenomenon as

a manifestation of intergroup conflict or violence (e.g., Levin \& McDevitt, 2002; Levin \& Rabrenovic, 2001) and as motivated by the distinctiveness of the victim(s), because the offender only targets victims with different group memberships. This type of conceptualization of HC has influenced both clinical interventions with victims of hate crime and the research focus on the causality of hate crime. (Sun, 2006, p. 598)

As regard HCs provoked by the disability of the victim, there is evidence to support the claim that disabled people are at a higher risk of targeted violence, harassment and abuse (Goodley \& Runswick-Cole, 2011; Sin et al., 2010). The studies concerned with HCs focus on "minority-victimology", especially, with the construct of a disability hate crime (DHC) and its relative legislative declinations. In 2007, the UK public agency the Crown Prosecution Service (CPS) defined a DHC as 'any incident which is perceived to be based upon prejudice towards or hatred of the victim because of their disability or so perceived by the victim or any other person' (CPS, 2007, p. 7, cit. in Roulstone, Thomas, \& Balderston, 2011, p. 355). Moreover, in 2016, the Association of Chief Police Officers defined a DHC as a criminal offence perceived by the victim, or others, to be motivated by hostility or prejudice underpinned by a person's disability or perceived disability (Hall, 2018; Ralph, Capewell, \& Bonnet, 2016). Furthermore, the following year, the aforementioned CPS framed DHC as a crime carried out by a perpetrator's hostility towards the victim's disability, and their actual or perceived impairments (CPS, 2017). Furthermore, the definitions of DHCs converge into the semantic areas of discriminatory, unfair, abusive and violent behaviors aimed at people with disabilities, arising from beliefs characterizing people with impairments as a minority (Ralph, Capewell, \& Bonnet, 2016).

Consequently, there are two major interrelated issues concerning the criminal justice system and the criminological literature about DHC: (a) the absence of strong criteria with the capability to certify-through the police and the criminal justice system - whether or not a reported crime is motivated by prejudice or hostility towards the victim's disability, and (b) the seemingly peripheral nature of DHCs as an area of research in criminological inquiry (Roulstone \& Mason-Bish, 2013) because of it being anchored to the idea of "victimology", which dominates the discourse on HC (Gerstenfield, 2013).

A lack of a clear and common definition of DHCs and a parallel inconsistent response from the police and criminal justice system (Sin, 2016) leads such crimes to be under-reported in the official crime statistics when compared with the crimes related to ethnicity, color, religion, sexual orientation, gender, or national origin (Emerson \& Roulstone, 2014; Shakespeare, 2012; Sin et al., 
2010, 2012; Sin, 2016; Ralph et al., 2016; Richardson, et al., 2016). As Hall (2018) reported, the large-scale Crime Survey for England and Wales estimated that 62,000 DHC incidents occurred between 2012 and 2013, while, in the same period, the police recorded 1,841 such cases. Furthermore, Brereton (2013) highlights the misunderstandings among the agencies concerning what constitutes a DHC. Moreover, policy definitions lead to confusion and a lack of confidence in crime reporting (Brereton, 2013), and some authors highlight that there is a dearth of an effective multi-agency response (Richardson et al., 2016; Sin et al., 2010; Sin, 2016). Finally, Shakespeare (2012) suggests the scarcity of awareness about disability among the officers and the fact that people with disabilities are not considered credible witnesses, along with the inaccessibility of facilities, are the critical factors responsible for the lack of an adequate response from the authorities.

With respect to the dominance of "victimology" in HC discourses (Gerstenfield, 2013), several authors have problematized how most of the studies in this area focus more on victimization-i.e., an ingrained and inherent "vulnerability" —as an element of violence perpetrated against disabled people and less on those who commits these crimes and the locations and time in which they occur (Gerstenfield, 2013; Hall, 2018; Jenness, 1999, 2001; Macdonald, 2015; Roulstone et al., 2011). For instance, Macdonald (2015) notices how the notion of vulnerability may become a barrier within the legal system's preventive strategies that are meant to recognize DHCs. Macdonald's study discloses the risk of neglecting the fact that the hostility is aimed at disabled people, which stops disabled people from gaining full legal protection. Even though approaching the victims with a critical gaze is of primary importance during legal and/or criminal investigation, failing to critically look at that those who offend, i.e., the 'anonymous hateful', may lead to the consolidation of the prominent image of the offenders. Moreover, this approach may disregard the relationship between the victims and offenders, as well as the socio-spatial context in which DHCs occur, along with the entrenched social factors underpinning this phenomenon (Garland, 2012; Gerstenfield, 2013, Hall, 2018, Macdonald, 2015; Sin et al., 2010).

From Waxman's (1991) study on violence towards disabled people to the 2016 report from the Equality and Human Rights Commission (EHRC), DHCs and violence have been treated as ongoing social phenomena and parts of a much broader set of exclusionary practices that a disablist society suffers from (EHRC, 2016; Hollomotz, 2013; Roulstone \& Mason-Bish, 2013). This points to the fact that considering impairments per se as elements that trigger violence, harassment, abuse, etc. signifies a neglect towards the nuanced understanding of situational risks as well as the social background in which these events occur (Sin et al., 2010). As a social fact, the crime must be placed within space-time coordinates, a geographical space constituted by encounters between people's shared meanings, complex interactions between impairments, the wider social attitudes and behaviors of the actors, as well as the environmental and structural conditions (Hall, 2018; Sin, 2016). 
Even while acknowledging the relevance of studies that focus on disabled people by presuming them as vulnerable persons (Iudici, Bertoli, \& Faccio, 2017; Roulstone et al., 2011), this review chose to focus on the "dark side" or the "overshadowed background" of the literature on disability and crime. In fact, despite the fear, harassment, and violence permeating the everyday lives of many disabled people in private as well as public places (EHRC, 2016), most studies often neglect the role of environments in facilitating or hindering DHCs, situating these violent acts against disabled individuals in anonymous physical settings (Hall, 2018; Sin et al., 2010). Although it has been seen as a necessity to locate disability as a cultural and political phenomenon contextualized within society, there are practically no studies about the socio-spatial dynamics of DHCs (Alhaboby, al-Khateeb, Barnes, \& Short, 2016; Goodley \& Runswick-Cole, 2011; Hall, 2018; Ralph et al., 2016; Roulstone \& Mason-Bish, 2013). Therefore, this aspect of the social context remains under-represented in the studies on DHCs. This discloses the necessity of exploring this overshadowed area in order to assess its theoretical and practical implication in appropriately addressing DHCs. Thus, in this research we ascertain whether and how public places have been taken into account in DHC studies, with a focus on the kind of impact these places may have in hindering or facilitating these phenomena. The extant literature is reviewed to identify any potential relationship between DHCs and the public environments and, wherever appropriate, we reported the type of crimes or the preventive strategies characterizing these spaces.

\section{Theoretical frameworks dealing with disability}

There are two major theoretical frameworks or models, the medical and the social model, which are concerned with and inform the idea of "disability". The latter underlines the role of society in producing the disability in individuals that suffer from impairments, while the former places the cause of the deficit within the individual (Brittain, 2004; Forhan, 2009; Haegele \& Hodge, 2016; Roulstone \& Mason-Bish, 2013). Regardless of their differences, both perspectives have been subjected to several critiques (Haegele \& Hodge, 2016). The major criticism against both models is that they ignore the relationship between social experience and the fact of owning an impaired body with which other persons interact on interpersonal, social, cultural, economic and political levels (Marks, 1999; Haegele \& Hodge, 2016).

As regards the background of HCs, the EHRC identifies both socio-psychological and structural perspectives, i.e., the structural factors that may have an impact on HCs (which includes online or cyber hate crimes), along with identifying "how certain social processes (e.g., societal norms and values), and practices (e.g., the practices and interventions used by statutory agencies) may actually create a social context in which certain groups in society can become marginalized or stigmatized" (EHRC, 2016, p. 8). In this perspective, perceived or actual threats can be linked not only to economic stability and access to social resources, but also to people's sense of safety in the society and/or 
values and social norms. Through this perspective, DHCs are shaped as an ongoing process that often forms a part of the everyday experiences of hostility and prejudice faced by people with disabilities (EHRC, 2016).

To overcome the dichotomous medical-social framework, and in accordance with the mutual relationship between these theoretical approaches towards disability and HC highlighted by EHRC (2016), we chose to adopt an interactionist epistemological theoretical framework (Salvini \& Dondoni, 2011; Salvini, 2004) for the research, especially in the results and conclusions sections. According to the interactionist assumptions, reality cannot be separate from discourses (i.e., rules, roles, meanings, acts and actions of which each human being is simultaneously an actor and interpreter) that name and describe reality. In doing so, the discourse creates pragmatic effects (Salvini \& Dondoni, 2011; Salvini, 2004). Interaction, between the parts of every kind of system, is considered the main object of this theoretical framework, and language is considered to be the principal means of representing the state of social reality. The reality lived by individuals, in which they relate to each other not only through the discourses but also through the social situation in which they meet, is shaped by their own scripts, structures, schemes, narrative genres, conceptual architectures and physical or symbolic artefacts (Faccio, Iudici, Turco, Mazzucato, \& Castelnuovo, 2017; Turchi \& Perno, 2004; Turchi, 2009). As Haegele and Hodge (2016) highlight, it is the language that people use to describe those with disabilities that influences their expectations of and interactions with disabled people.

\subsection{Method}

\section{Scoping literature review}

Since this study aimed to explore whether public places have been taken into account in studies on DHCs and in what manner, a scoping literature review was chosen as the most suitable research strategy to accomplish this goal (Carr et al., 2017; Grant \& Booth, 2009). This strategy entails a preliminary assessment and a synthesis of research findings available in literature about a specific topic.

Furthermore, the choice has been made due to the paucity of studies concerning the object of this study. This method helps a researcher identify what has been accomplished previously, allowing for further identification of omissions or gaps for other researchers to build on (Grant \& Booth, 2009). To implement this research strategy, the recent or current literature was examined, identified and consolidated, with a focus on whether public places have had an impact on the studies on DHCs and if so, how (Grant \& Booth, 2009; Lipscomb, 2000). The major criterion for the selection of the studies for this review was that the research was peer-reviewed (Grant \& Booth, 2009). The aim of this kind of review was to explore and systematize the available data on the area to discover the lines along which future research can fill the identified gaps and omissions in the existing literature. 


\section{Data collection}

In order to investigate whether public places have been taken into account in the literature on DHCs we utilized the Scopus and PubMed databases to identify the role of public places in facilitating the occurrence of DHCs. We relied on these two databases to ensure the quality of the literature selected for the review and, as the other browsers opened to more complex and specific aspects, to not hinder the generalizability of this exploratory study. Due to the paucity of studies concerning precisely the object of this study, which is intended to be the first exploratory overview of this phenomenon, the authors of the current study first defined their main object of inquiry, namely public place. In order to do so, they drew on the definition provided by the Cambridge Dictionary (Cambridge University Press, 2019) as well as on their theoretical framework (Salvini, 2004) to define public place as every space (area, town, building, etc.). That is, physically or virtually, space meant and provided by the government to be available to everyone and which enables symbolic interactions between two or more ordinary people by rules, roles, meanings, acts, and actions characterizing a specific space. Second, all the studies that regarded the role of public places in DHCs or even mentioned them in passing were considered. Additionally, any kind of discrimination over type of disability, gender, nature, crimes, etc. was strictly avoided.

The articles were identified by searching for the main keyword "disability hate crime" and limited to printed articles, reviews, notes and editorials. The abstracts of the 95 selected documents were reviewed independently by the two authors. The aforementioned definition of a public place has been used by the authors to include those papers that reported the kind of pertinent spaces encompassed by our definition. In this preliminary abstract selection, given the exploratory value of this study and the paucity of studies concerning this topic, even articles that merely (or inexplicitly) mention the places of crimes were selected. In this step, the two authors discussed the retrieved abstract and used the definition of a public place to exclude 51 articles for:

(a) not being consistent with the research aim;

(b) not referring to any public place as the scene of the DHC;

(c) not being consistent with the definition of a public place provided by the authors and

(d) being duplicated.

Due to the paucity of studies, all the remaining 44 articles formed the sample for this review. These articles were published within a span of 27 years, between 1991 and 2019, and were independently read by the two authors to extract quotes that were relevant to the research objective. After a comparison between the two authors, the above step revealed that 19 articles did not refer to any public place related to DHCs. Therefore, this left the authors with only 25 papers for their consideration. In an effort to locate relevant articles not found 
in our search, and to give a wider introductive perspective, Scholar database was also searched, retrieving two relevant articles. Finally, the authors read the papers $(N=27)$ independently to identify the macro-themes representing how public places have been taken into account in the studies on DHCs, with a focus on how they are hindering or facilitating these phenomena. Finally, according to the criterion of greater representativeness of the collected data, the data were categorized into three macro categories: (a) public places as the backdrop to DHC occurrences; (b) public places as an active factor in facilitating DHC occurrences; and (c) public places as an active factor in hindering DHC occurrences. The authors then worked independently to present the study as the product of cross-comparison between the findings of the authors.

\subsection{Results}

Of the 32 initially identified publications that concerned DHC, only 20 were eligible for inclusion as they concern public places. Their content was organized in the three aforementioned categories.

From the data in the first category (public places as the backdrop to DHC occurrence), the authors gathered those articles that referred to public places where DHCs were most likely to occur. In the second category (public places as an active factor in facilitating DHC occurrences), the authors counted four contributions that highlight how the features of public places might have facilitated the perpetration of DHC. Finally, the last category (public places as an active factor in hindering DHC occurrences) contained those studies that considered which actions to take in public places, considering them as locations on which counter-strategies can be based to prevent DHCs.

\section{Public places as the backdrop to DHC occurrences}

In the literature, there were studies that shed light on an underground public dimension related to DHCs that has been overlooked in the studies about vulnerability and domestic violence against disabled people. As reported by Hall (2018), the following public locations in Kent (southeast England) have been described as places "where bad things happen" to people with learning disabilities: "school, college or day center $(43 \%)$; in the street as they were walking somewhere $(35 \%)$; in and around their homes $(28 \%)$; in their neighborhood $(28 \%)$; and on public transport (25\%)" (Hall, 2018, p. 4). This example underlines the fact that acts of abjection experienced by disabled people may occur everywhere, not only in private locations. Waxman (1991) was perhaps the first to shed light on the public dimension of violence against people with disability, and reported two cases of routine physical abuse in public places, namely a school and the outside of a local library. In particular, he described the episode of the murder of Cary Dickenson, a person with multiple disabilities, whose body was found in the trash can of a local library. Another instance was that of a student in Northern California, who had been repeatedly thrown in a cold pool 


\section{Antonio Indici and Riccardo Girolimetto}

by the teaching staff. Besides these locations, institutional care-place and workplace have been mentioned as other backdrops that prove that disabled people do not face violence only in domestic or private contexts (Waxman, 1991).

In accordance with the above-mentioned places, the annual Hate Crime Statistic reports, whose data for the five-year period between 1997 and 2001 were collected, identified school environment (college campus) (OR 0.10435) as the primary location of $\mathrm{HC}$ incidents, along with streets (OR 0.17593), residences (OR 0.58750) and government buildings (OR 0.02419) (McMahon et al., 2004). Since this data were used by McMahon and colleagues (2004) to examine the prevalence of DHCs compared with other kinds of HCs, they only provide a statistical correlation between crimes and places and do not explain the kind of impact specific locations have on violence.

Besides mentioning schools, workplaces and streets as the places where violent acts against people with disability occur, other studies identify locations such as public transport, high streets, social housing/community and institutions (such as those in the mental health system) (Carr et al., 2017; Clement et al., 2011; Hall, 2018; Mikton, Maguire \& Shakespeare, 2014; Roulstone et al., 2011; Shakespeare, 2012). As regards public transport, Clement and colleagues (2011) also noted the kind of violence (verbal) that is related to it by quoting the following lines from a victim: "I did say to, I think it was one of the inspector or whatever, well 'this train is overcrowded and I can't breathe' then I heard a bloke saying 'oh is the lunatic asking about the overcrowding" (Clement et al., 2011, p. 220). A more stirring example of DHCs occurring in a public location was described by Sherry (2013), which took place in a shopping center. In this case, two boys met and escorted a girl with disabilities to the local river, where a larger group subjected her to physical abuse.

As regards DHCs occurring in communities and institutions, in their systematic review, Mikton, Maguire, and Shakespeare (2014) reported a strong paucity in current literature about these events in spite of their prevalence. In fact, since a UNICEF report of 2005, widespread violence against disabled children in institutions (Mikton et al., 2014) and communities (Carr et al., 2017; Shakespeare, 2012; Garland, 2012) seems to be a proven fact; particularly as in these places, many disabled people live in isolation in vulnerable conditions (Shakespeare, 2012).

\section{Public places as active factors in facilitating $\mathrm{DHCs}$}

In the previous section, the authors limited their focus on those studies which mentioned the most likely scenes of DHC. Now, this study will refer to those articles that report how a specific location may facilitate DHC occurrences. By dealing with public places as crucial factors in violent acts against disabled people, this study identified and assessed three major places considered in the literature in terms of the contributing factors that may lead to different kinds of violence: public institutions, areas of poverty and deprivation, and virtual spaces. 
As regards public institutions (such as residential/community setting and school system), when they become segregated and exclusionary they may fail to recognize the diversity of their residents and, consequently, fail to restrain violence against the users and build bonds and safe spaces that safeguard the specificity and differences of identities (Balderston, 2014; Goodley \& Runswick-Cole, 2011). For instance, in user-led research involving disabled women who have experienced violence in segregated institutions (health, educational, and residential) and across impairment groups, Balderston (2014) reported how, in these spaces, a lack of control over the choice of personal support staff, activities, money, transport, etc. may increase the risk of sexual violence and, at the same time, decrease the possibility of safety (Balderston, 2014). Furthermore, other studies highlight the frequency of sexual abuse against people with disabilities in an institutional setting (such as day centers or residential homes) and the critical role of health and social care professionals in the prevention of sexual abuse (Balderston, 2014; Carr et al., 2017; Hall, 2018; Roulstone \& Mason-Bish, 2013; Sin et al., 2010; Sin, 2016). For instance, a care giver may display controlling behaviors such as controlling finances and removing the wheelchair of the one being cared for, that might not appear criminal (Roulstone \& Mason-Bish, 2013). When the perpetrator is a 'care giver', it does make one rethink how a dependent relationship, by its context, may give rise to an increased risk of abuse in a care-giving situation (Carr et al., 2017; Sin et al., 2010).

As for the school system, the current review identified the work of Goodley \& Runswick-Cole (2011) as the only study that focused on school-related violence outside of the common ways of studying the topic of bullying against people with disabilities. First, they identified the promotion of cost effectiveness and efficiency performance required as the structural characteristics that may lead to greater competition, selection, and social division to facilitate the retention of the disparity between the abled and the disabled learners (Goodley \& Runswick-Cole, 2011). Second, the nationalization of curricula across schools could create a logic of promoting key skills among the students to make them fit for advanced capitalistic societies (Goodley \& Runswick-Cole, 2011).

Furthermore, our focus on areas of poverty and deprivation revealed that inappropriate public housing or disproportionate institutionalization of disabled people can either lead to the production of social marginalization and isolation or accentuate the power imbalance between the actors who inhabit those places (Balderston, 2014; Hall, 2018; Macdonald, Donovan \& Clayton, 2017; Sin, 2016; Sin et al., 2010). As regards poor housing and deprived areas, the literature revealed a correlation between them and the occurrence of DHCs (Chakraborti \& Garland, 2012; Emerson \& Roulstone, 2014; Hall, 2018; Macdonald et al., 2017). For instance, a study by Macdonald et al. (2017) found a significant correlation between DHCs and the most deprived areas in Newcastle and Sunderland (i.e., 33 percent of all the incidents reported to Agencies against Racist Crime and Harassment, ARCH). Moreover, they reported that, among disabled people, there was a perceived fear of being sent to a more restrictive setting such as residential care (Macdonald et al., 2017). By observing social factors that may 


\section{Antonio Indici and Riccardo Girolimetto}

lead to different forms of violence in such spaces of segregation and deprivation, the difficulty in building local networks that may get people to engage in the prevention of anti-social behaviors can be noticed (Sin et al., 2010). Others have also highlighted the risk of isolation and marginalization of the people living in independent social housing sectors, often characterized by the provision of inflexible and inappropriate services (Macdonald et al., 2017; Sin, 2016; Sin et al., 2010), and the anticipation concerning the situational vulnerability risk involved in collocating disabled people in such places based on choices made by professionals involved in the housing decision (Sin, 2016).

Moreover, regarding the occurrence of a higher incidence of DHCs in these areas, some authors propose (a) the changing levels of diversity among the different marginalized communities living in close contact, underpinned by poverty; (b) the withdrawal of jobs and services; and (c) the climate of suspicion and marginalization as factors contributing to this problem (Hall, 2018; Macdonald et al., 2017). These conditions may underpin and lead to disabling social barriers, such as the dynamics of the tensions between different ethnicities as well as the risk of victimization, abuse, violence and harassment (Macdonald et al., 2017; Sin, 2016; Sin et al., 2010). Frequent examples of violent practices include intimidation, aggression, offensive language, as well as harassment and abuse. Sin et al. (2010) report the following forms of harassment in a case they studied: "house burgled, lit matches were thrown through their letter box, and used condoms, excrement and abusive letters delivered to their front door" (Sin et al., 2010, p. 21).

Advancements in digital technology, the internet and electronic communications introduced brand new virtual public spaces and commonplace means for interpersonal interaction. The spread of these tech-practices all over the world spawned new forms of violence. As the EHRC (2016) stated, cyber hate is a growing phenomenon which vastly outnumbers offline HCs. This study has drawn upon previous studies regarding digital communication channels, virtual environments and offender's anonymity to examine a new kind of online location that may give rise to vulnerable situations (Alhaboby et al., 2016, 2017a, 2017b; Burnap \& Williams, 2016). Creating fake accounts pretending to have a disability, targeting the victim's significant others, threatening victims and spreading false information are some examples of the prevarication strategies that are made possible through virtual spaces of interaction. Moreover, such virtual prevarication strategies may lead to social isolation, cyber harassment, hate speech and have a wider impact on the wellbeing of the victim (Alhaboby et al., 2017a). This may further result in distress, anxiety, mood disturbances, deterioration of health, suicide attempts and a lack of awareness/education/ training in supporting others (e.g., groups, police and healthcare professionals) (Alhaboby et al., 2016, 2017b; Burnap \& Williams, 2016).

\section{Public places as an active factor in limiting DHCs}

After describing how the characteristics of some public places may facilitate the perpetration of DHCs, the current study concentrates on how the structural 
conditions of such places may limit violence, harassment, abuse and crime. The focus of the study is on educational and virtual environments because, on the databases we utilized, no study that takes deprivation and poor housing into account from this perspective was found.

With regard to public places, such as local libraries across the city, and commercial and business premises, McClimens and Brewster (2017) proposed to consider these places as first accessible refuge zones, where staff in various commercial and business premises along the 'High St.' could offered support, in cooperation with the local police.

Based on the best practices addressing stigmatizing and discriminatory attitudes towards disabled people, certain formative and informative interventions (Richardson et al., 2016), in partnership with the police and experts, can make an educational environment a safe space by promoting a shift among the students about the idea of disability from an individual to a socio-relational and contextualized perspective. Maguire, Wilson, and Jahoda (2018) recommend the use of school-based lessons or an informed program of lessons as a strategy to address the stigma and discriminatory attitudes related to disability and also as a means to influence the views of the wider community of which the schools are a part (Maguire et al., 2018). The crucial issues that these interventions may focus on include (a) tackling the linguistic barrier that may produce stigmatizing labels that give rise to social exclusion/bullying/hate crime, (b) building partnerships for pooling resource (e.g., public agencies), and (c) paying attention to the structural factors that may lead young people towards marginalization (Maguire et al., 2018; Richardson et al., 2016). To support people with disabilities, and for citizens to feel more confident about recognizing and reporting DHCs, Maguire and colleagues (2018) analyzed other existing practices such as school assemblies as occasions to raise awareness about bullying and DHCs in synergy with statutory agencies (e.g., the police) and theatre workshops. Moreover, they illustrated a school intervention program that was developed in collaboration with teachers and educators, which included reflection sessions to understand the attitudes and behaviors of the students, and lessons dealing with the appreciation of difference and disability and the meaning of having a disability, with the aim of increasing the contact between the able-bodied and disabled persons (Maguire et al., 2018).

Furthermore, other suggestions came from Clement et al. (2011), who reported the use of HC posters in schools, which aimed not only to encourage the reporting of targeted harassment suffered by disabled people but also to send out messages to potential perpetrators. When the researchers asked the participants with intellectual disabilities to think about what would stop or prevent their harassment, they suggested school and community education, along with a change in public attitudes and more effective policing as the possible solutions (Clement et al., 2011). Similarly, Sin et al. (2010) pointed out the crucial role of the educational environment in challenging and preventing harassment and violent acts against people with disabilities, through effective policies offering support to those who report bullying or hate-related incidents (Sin et al., 2010). 


\section{6}

As for virtual public spaces such as social media, blogs, email channels and other instant messaging services, few studies have reported how the new virtual form of communication (e.g., social networking sites such as Twitter, Facebook, etc.) may be used as a medium to implement diagnostic prevention systems to promptly identify hate speech, threats, harassment, etc. (Alhaboby et al., 2016, 2017a; Burnap and Williams, 2016). For example, social media and victim support websites may become an effective way to explore the experiences of the disabled victims of cyber harassment to analyze the impact of cyber harassment on their lives with the help of a self-administered online survey (Alhaboby et al., 2016).

Furthermore, Burnap and Williams (2016) developed a supervised machine classification model for multiple protected characteristics (i.e., gender, ethnicity, disability, sexual orientation) to automatically identify instances of cyber hate posted to online social networks such as Twitter. Additionally, they suggest the development of a blended model that includes the knowledge of how the aforementioned protected characteristics may intersect with each other in cyber hate speech (Burnap \& Williams, 2016). From this perspective, Twitter is framed as a digital agora that promotes real-time interactions between larger groups of people and, therefore, is a suitable source of data (Burnap \& Williams, 2016).

\subsection{Conclusions and recommendations}

It is evident from the results that the lack of understanding of the context in which DHCs occur must be considered in future studies that aim to face violence against people with disabilities. In fact, given the dearth of knowledge on the role played by public places in DHCs, there is a need to reframe the nature of this phenomenon as a contextualized event that is shaped by social relations between the abled/disabled in a specific space and time. Future research should therefore take into account socio-spatial dynamics of DHCs, as well as the inherent social architecture and policies that seem closer to a disablist society than an inclusive one.

In short, concerning public places as an active factor in facilitating DHC occurrences, we noted:

1. A neglect of the situational vulnerability risk involved disabled people living in independent social housing sectors;

2. A critical impact of the care-giving situations (such as day centers or residential homes) where the increased dependency and the a lack of control over users' personal choices, may give rise to risk of abuse, decreasing the feelings of safety;

3. The role of the school system in promoting cost effectiveness and efficiency performance required within standardized criteria;

4. The impact of social networks in creating a situation of cyber harassment, cyber-hate speech and social isolation of the victims. 
With regard to public places as an active factor in hindering DHC occurrence, the following observations were made.

1. The crucial role of the educational environment in challenging and preventing harassment and violent acts against people with disabilities, in synergy with statutory agencies and an active role of students (e.g., theatre workshops).

2. The value of the cooperation between local police and local stores along main streets in the implementation of first accessible refuge zones, as suggested by McClimens and Brewster (2017) in the previous section. Public place as an active factor in limiting DHCs.

3. The possibility to use the internet and social networks as suitable sources of data for case-analysis and for monitoring DHC policies, as well as mediums to accommodate disabled people's needs by online research methods and interviews.

The reported observations shed light on the evident impact of public spaces in setting up the conditions for a vulnerability situation involving people with disabilities, along with the importance of taking into account the structural elements of those spaces in which DHCs occur.

Before considering new preventive practices, we should consider that, in order to safeguard specific special rights, society is involved in a creating and using process of differences and subdivisions based on the abled/disabled dichotomy as human characteristics, ignoring the contextual conditions that can produce disability. For instance, wheelchair spaces on public transport and other so-called "designated" disability spaces, poor housing in deprivation areas and schools that promote cost-effectiveness and efficient performance give rise to competition and social division between the able-bodied and the disabled. These are not spaces of inclusion but places where implicit traces mark the differences, and this may lead to exclusionary behaviors. It is the interaction of those using these places that make them what they are in a socio-symbolic negotiation of meanings.

Consistent with other researchers, we consider DHC as a social fact; hence, it is a product of the interactions between the victim and the perpetrator(s) in specific spaces and times that portrays disabled people as welfare recipients and individuals favored in the access to resources (e.g., Haegele \& Hodge, 2016; Hall, 2018; Jenness, 2001; Ralph et al., 2016; Salvini \& Dondoni, 2011). This is the reason why the authors of the current study propose a shift from inherent vulnerability to situational vulnerability (Hall, 2018; Sin et al., 2010; Sin, 2016). This perspective shift means not taking for granted where and when crimes and haterelated practices occur, as well as how places impact on them, by wondering whether attribution errors, false beliefs and stereotypes related to "vulnerability" and "disability" may constitute implicit assumptions in those policies that concern people with disabilities (e.g., school programs, social housing collocation process, care-giving situations) (Chakraborti \& Garland, 2012; Garland, 2012; Iudici \& Renzi, 2015; Iudici, Favaretto, \& Turchi, 2018; Ralph et al., 2016; Iudici, Antonello, \& Turchi, 2019). In addition, public places could represent a strategy 


\section{8}

for tackling DHCs, for example by the implementation of accessible refuge zones into urban areas. This implies a multi-agency working (Richardson et al., 2016; Sin et al., 2010; Sin, 2016) in order to involve all the social actors (i.e., social services, police, counsellors, therapists, disability experts, families, people with disability and the perpetrators of DHC) that inhabit specific places and constitute them as well as their dynamics. Therefore, the main aim of this study is to promote a new inclusive way to address DHC.

With regard to limitations, we consider our definition of public places as a restriction since it has been assembled by a specific theoretical framework, which has an inevitable impact on the generalizability of this study. Furthermore, we must consider the fact that collecting data from only few databases (Scopus, PubMed and Scholar) limits the possibility to draw upon different points of view concerning the area of research. Finally, concerning our research strategy (Grant \& Booth, 2009), conclusions may be impacted by content bias to the extent that significant sections of the literature may have been omitted by previous underlying authors' assumptions, or the validity of the statements made might not have been questioned.

Due to the paucity of studies taking into account public places as the main object of inquiry in DHC literature, the authors are of the view that future research can extend this inquiry to other sources of information, as well as engage this brand new line of research, maybe involving directly those social actors who live in places (both physical and virtual) where DHCs occur.

Given the crucial role of the social contexts in facilitating and hindering DHCs, we hope this explorative study may be useful for practitioners, and those who are involved in policies of intervention, in so far as we have tried to adopt and share a new perspective on this phenomena. The suggestions we make concern a shift from policies focusing on single actors (perpetrators or victims of DHCs) to policies regarding the whole social scenario, from the engagement of single experts for each disability to the involvement of all the actors in the contexts (virtual and physical), leaving labels behind, and starting a relationship between all territorial services to promote new inclusive ways to address DHCs.

\section{References}

Alhaboby, Z. A., al-Khateeb, H. M., Barnes, J., \& Short, E. (2016). 'The language is disgusting and they refer to my disability': the cyberharassment of disabled people. Disability \& Society, 31, 1138-1143.

Alhaboby, Z. A., Barnes, J., Evans, H., \& Short, E. (2017a). Cyber-victimization of people with chronic conditions and disabilities: a systematic review of scope and impact. Trauma, Violence, \& Abuse, 20, 398-415.

Alhaboby, Z. A., Barnes, J., Evans, H., \& Short, E. (2017b). Challenges facing online research: experiences from research concerning cyber-victimisation of people with disability. Cyberpsychology: Journal of Psychosocial Research on Cyberspace, 11, 1-8.

Balderston, S. (2014). Victimized again? Intersectionality and injustice in disabled women's lives after hate crime and rape. Gendered Perspectives on Conflict and Violence, 18, 17-51.

Brereton, S. (2013). Living in a different world: joint review of disability hate crime. Probation Journal, 345-350. 
Brittain, I. (2004). Perceptions of disability and their impact upon involvement in sport for people with disabilities at all levels. Journal of Sport and Social Issues, 28, 429-452.

Burnap, P., \& Williams, M. L. (2016). Us and them: identifying cyber hate on Twitter across multiple protected characteristics. EPJ Data Science, 5, 1-15.

Cambridge University Press (2019). Place | meaning in Cambridge Dictionary. https:// dictionary.cambridge.org/dictionary/english/place (accessed 20 February 2020).

Cambridge University Press (2019). Public | meaning in Cambridge Dictionary. https:// dictionary.cambridge.org/it/dizionario/inglese/public (accessed 20 February 2020).

Carr, S., Holley, J., Hafford-Letchfield, T., Faulkner, A., Gould, D., Khisa, C., \& Megele, C. (2017). Mental health service user experiences of targeted violence and hostility and help-seeking in the UK: a scoping review. Global Mental Health, e25, 1-20.

Chakraborti, N., \& Garland, J. (2012). Reconceptualizing hate crime victimization through the lens of vulnerability and 'difference'. Theoretical Criminology, 16, 499-514.

Clement, S., Brohan, E., Sayce, L., Pool, J., \& Thornicroft, G. (2011). Disability hate crime and targeted violence and hostility: a mental health and discrimination perspective. Journal of Mental Health, 20, 219-225.

CPS, T. C. (2017, August 25). Online Support Guide for Disabled Victims and Witnesses of Crime. CPS: www.cps.gov.uk/sites/default/files/documents/publications/guide-tosupport-for-disabled-victims-and-witnesses-of-crime.pdf (accessed 10 January 2020).

Emerson, E., \& Roulstone, A. (2014). Developing an evidence base for violent and disablist hate crime in Britain: findings from the life opportunities survey. Journal of Interpersonal Violence, 29, 1-19.

Equality and Human Rights Commission (EHRC) (2016). Causes and motivations of hate crime. www.equalityhumanrights.com/en/publication-download/research-report102-causes-and-motivations-hate-crime (accessed 16 December 2019).

Faccio, E., Iudici, A., Turco, F., Mazzucato, M., \& Castelnuovo, G. (2017). What works for promoting health at school: improving programs against the substance abuse. Frontiers in Psychology, 8, 1743.

Forhan, M. (2009). An analysis of disability models and the application of the ICF to obesity. Disability and Rehabilitation, 31, 1382-1388.

Garland, J. (2012). Dilemmas in defining hate crime victimisation. International Review of Victimology, 18, 25-37.

Gerstenfield, P. (2013). Hate Crimes: Causes, Controls and Controversies. London: Sage.

Goodley, D., \& Runswick-Cole, K. (2011). The violence of disabilism. Sociology of Health of Illness, 33, 602-617.

Grant, M. J., \& Booth, A. (2009). A typology of reviews: an analysis of 14 review types and associated methodologies. Health Information and Libraries Journal, 26, 91-108.

Haegele, J. A., \& Hodge, S. (2016). Disability discourse: overview and critiques of the medical and social models. Quest, 68, 193-206.

Hall, E. (2018). A critical geography of disability hate crime. Area, 51, 1-8.

Hollomotz, A. (2013). Disability and the continuum of violence. In A. Roulstone, \& H. Mason-Bish (Eds.), Disability, Hate Crime and Violence. London and New York: Routledge, 52-63.

Iudici, A., \& Renzi, C. (2015). The configuration of job placement for people with disabilities in the current economic contingencies in Italy: social and clinical implications for health. Disability and Health Journal, 8, 586-593.

Iudici, A., Bertoli, L., \& Faccio, E. (2017). The 'invisible' needs of women with disabilities in transportation systems. Crime Prevention and Community Safety, 19, 264-275.

Iudici, A., Favaretto, G., \& Turchi, G. P. (2018). Community perspective: how volunteers, professionals, families and the general population construct disability: social, clinical and health implications. Disability and Health Journal, 12, 171-179. 
Iudici, A., Antonello, A., \& Turchi, G. (2019). Intimate partner violence against disabled persons: clinical and health impact, intersections, issues and intervention strategies. Sexuality \& Culture, 23, 684-704.

Jenness, V. (1999). Managing differences and making legislation: social movements and the racialization, sexualization, and gendering of federal hate crime law in the U.S., 1985-1998. Social Problems, 46, 548-571.

Jenness, V. (2001). The hate crime canon and beyond: a critical assessment. Law and Critique, 12, 279-308.

Levin, J., \& McDevitt, J. (2002). Hate Crimes Revisited: American's War against Those who are Different. Boulder, CO: Westview.

Levin, J., \& Rabrenovic, G. (2001). Hate crimes and ethnic conflict: a comparative perspective. American Behavioral Scientist, 45, 574-755.

Lipscomb, C. E. (2000). Medical Subject Headings (MeSH). Bulletin of the Medical Library Association, 88, 265-266.

McClimens, A., \& Brewster, J. (2017). Intellectual disability, hate crime and other social constructions: a view from South Yorkshire. Journal of Intellectual Disabilities, 23(4), 486-497.

Macdonald, S. (2015). 'Community fear and harassment': learning difficulties and hate crime incidents in the north-east of England. Disability \& Society, 30, 353-367.

Macdonald, S. J., Donovan, C., \& Clayton, J. (2017). The disability bias: understanding the context of hate in comparison with other minority populations. Disability \& Society, 32, 483-499.

Maguire, R., Wilson, A., \& Jahoda, A. (2018). Talking about learning disability: promoting positive perceptions of people with intellectual disabilities in Scottish schools. International Journal of Developmental Disabilities, 65, 257-264.

Marks, D. (1999). Dimensions of oppression: theorising the embodied subject. Disability o Society, 14, 611-626.

McMahon, B. T., West, S. L., Lewis, A. N., Armstrong, A. J., \& Conway, J. P. (2004). Hate crimes and disability in America. Rehabilitation Counseling Bulletin, 47, 66-75.

Mikton, C., Maguire, H., \& Shakespeare. (2014). A systematic review of effectiveness of interventions to prevent and respond to violence against persons with disabilities. Journal of Interpersonal Violence, 29, 3207-3226.

Ralph, S., Capewell, C., \& Bonnet, E. (2016). Disability hate crime: persecuted for difference. British Journal of Special Education, 43, 215-232.

Richardson, L., Beadle-Brown, J., Bradshaw, J., Guest, C., Malovic, A., \& Himmerich, J. (2016). "I felt that I deserved it"-experiences and implications of disability hate crime. Tizard Learning Disability Review, 21, 80-88.

Roulstone, A., \& Mason-Bish, H. (2013). Disability, hate crime and violence. In A. Roulstone, \& H. Mason-Bish (Eds.), Disability, Hate Crime and Violence. London and New York: Routledge, 1-7.

Roulstone, A., Thomas, P., \& Balderston, S. (2011). Between hate and vulnerability: unpacking the British criminal justice system's construction of disablist hate crime. Disability \& Society, 26, 351-364.

Salvini, A. (2004). Psicologia Clinica (II ed.). Padova: Domeneghini Editore.

Salvini, A., \& Dondoni, M. (2011). Psicologia clinica dell'interazione e psicoterapia. Firenze: Giunti Editore.

Shakespeare, T. (2012). Blaming the victim: disability hate crime. Lancet, 380, 878.

Sherry, M. (2013). Feminist reflections on disability hate crime. Gendered Perspectives on Conflict and Violence: Part A (Advances in Gender Research), 18A, 53-66.

Sin, C. H. (2016). Commentary on "I felt I deserved it'-experiences and implications of disability hate crime". Tizard Learning Disability Review, 21, 89-94. 
Sin, C. H., Mguni, N., Cook, C., Comber, N., \& Hedges, A. (2010). Targeted violence, harassment and abuse against people with learning disabilities in Great Britain. Tizard Learning Disability Review, 15, 17-27.

Sin, C. H., Sheikh, S., \& Khanna, M. (2012). Police readiness for tackling hate crime against people with learning disabilities-areas for improvement and examples of good practice. Safer Communities, 11, 145-153.

Sun, K. (2006). The legal definition of hate crime and the hate offender's distorted cognitions. Issues in Mental Health Nursing, 27, 597-604.

Turchi, G. P. (2009). Dati senza numeri. Per una metodologia di analisi dei dati informatizzati testuali: M.A.D.I.T. Bologna: Monduzzi Editore.

Turchi, G. P., \& Perno, A. (2004). Modello medico e psicopatologia come interrogativo. Padova: Upsel Domeneghini.

Waxman, B. F. (1991). Hatred: the unacknowledged dimension in violence against disabled people. Sexuality and Disability, 9, 185-199. 


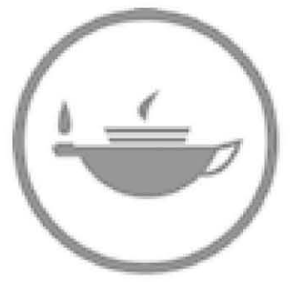

Taylor \& Francis Taylor \& Francis Group

http://taylorandfrancis.com 